\title{
EL PRIMER CUENTO MARXISTA PARA NIÑOS EN EL PERÚ: EL CASO DE "PACO YUNQUE" DE CÉSAR VALLEJO
}

\author{
THE FIRST MARXIST STORY FOR CHILDREN IN PERU: \\ THE CASE OF "PACO YUNQUE" BY CÉSAR VALLEJO
}

\section{JORGE VALENZUELA GARCÉS*}

\section{RESUMEN}

El objetivo de este estudio es demostrar que "Paco Yunque", de César Vallejo, es el primer cuento plenamente marxista para niños de nuestra tradición narrativa. Sustentamos esta tesis a partir del análisis del sistema ideológico presente en la historia, la funcionalización de los personajes y sus respectivos programas narrativos. Nuestro marco teórico comprende categorías propias del marxismo clásico. Finalmente, nos interesa problematizar el tipo de cuento que constituye "Paco Yunque" para sostener que, en su caso, estamos ante un relato que revoluciona el cuento infantil tradicional.

Palabras clave: "Paco Yunque”, César Vallejo, marxismo, literatura infantil.

\section{ABSTRACT}

The purpose of this study is to demonstrate that "Paco Yunque" by César Vallejo, is the first fully Marxist story for children of our narrative tradition. We maintain this thesis from the analysis of this ideological system that is present in history, the functionalization of the characters and their respective narrative programs. Our framework comprises categories belonging to classical Marxism. Finally, we want to problematize the type of story constituted by "Paco Yunque" to argue that, in this case, we face a story that revolutionizes the traditional fairy tale.

Key words: “Paco Yunque”, César Vallejo, Marxism, children’s literature.

Recibido: 11.09.13. Aceptado: 18.11.13. *om

* Universidad Nacional Mayor de San Marcos. Lima, Perú. E-mail: jorgevalenzuela4@hotmail. 


\section{GÉNESIS EDITORIAL DE “PACO YUNQUE”}

$\mathrm{T}$

ANTO el CUENTO "Paco Yunque" como la novela El tungsteno pertenecen al periodo que Luis Monguió (1960) calificó como el de más grande activismo político-literario de Vallejo. Es también el momento en que el autor de Trilce justifica plenamente la necesidad de producir y publicar narrativa de carácter proletario orientada, de manera abierta, a concientizar a los lectores respecto de situaciones insostenibles como la injusticia social ${ }^{1}$.

En 1930 expulsan a Vallejo de Francia por ser un militante ya abiertamente comunista y en 1931 se inscribe en el Partido Comunista español. Vive pues, en estos años, de manera apasionada la militancia partidaria comunista. En 1931, como una reafirmación de su fe en el marxismo realiza su tercer viaje a Rusia. Podría, sobre esta base, postularse que en ese momento Vallejo rechaza cualquier literatura cuya función no sea políticamente revolucionaria.

Según Georgette de Vallejo (1959: 18) el cuento "Paco Yunque" fue escrito en 1931, el mismo año de la publicación de la novela El tungsteno. El cuento, sostiene, fue escrito a pedido de la Editorial Cenit ${ }^{2}$, la misma que ya había publicado la novela antes mencionada. La referencia a que el texto fue escrito por Vallejo a petición de la editorial es reveladora en dos sentidos. El primero concierne a la forma en que la editorial gestionaba los títulos

\footnotetext{
${ }^{1}$ Esto ha llevado a muchos críticos a establecer la superioridad de su poesía (sobre todo la vanguardista) frente a su obra en prosa, precisamente por la fuerte dependencia del marxismo presente en ella. Esta posición parte del supuesto problemático de que la independencia ideológica garantiza la superioridad estética de un texto o, lo que es lo mismo, que la presencia de una determinada ideología en el campo de la creación literaria condena a los textos a ser inferiores en calidad, más aún si este tratamiento es explícito como en el caso de Vallejo. Habría que atender, más bien, para el análisis, al hecho de que la narrativa de Vallejo se produce en contextos muy determinados y que cumple una función política muy específica sobre la cual debería atenderse en aras de su justa valoración. Reparemos en el hecho de que "Paco Yunque", por decir lo menos, revoluciona la tradición del cuento para niños en toda Hispanoamérica, lo cual desde ya es un mérito incuestionable. Agreguemos a lo dicho, contra el error en el que suele incurrir la crítica, que tanto El tungsteno como "Paco Yunque" no se inscriben dentro del llamado "realismo socialista". Este tipo de realismo solo se practica a partir de 1934, año en que es adoptado oficialmente como un acuerdo del Congreso de Escritores Socialistas de la Unión Soviética. Los textos de Vallejo se escriben en 1931. Quizá esta última aclaración pueda explicar en algún sentido los prejuicios contra su obra narrativa.

${ }^{2} \mathrm{Al}$ revisar el catálogo de publicaciones de la Editorial Cenit es posible advertir la existencia de una colección de "Cuentos Cenit" para niños en la que, por ejemplo, publicó el escritor L. Pantaleiew muy publicitado por aquellos años. Esta comprobación hace más verosímil la versión de la viuda de Vallejo sobre la petición que la editorial le hizo al poeta sobre la escritura de un cuento para niños.
} 
que publicaba, lo cual no resulta una novedad si pensamos en las políticas comerciales y en los propios intereses ideológicos de la editorial. El segundo nos muestra la disposición de Vallejo a escribir textos por encargo a partir, ciertamente, de un previo compromiso con la causa del comunismo internacional que la Editorial Cenit, sin ninguna duda, fomentaba ${ }^{3}$. Como quiera que fuese, está claro que la militancia de Vallejo lo acercó a esa editorial y que si aceptó el encargo de escribir un cuento para niños fue por la orientación comunista de la casa editora y por su fe en el marxismo. Este es el argumento más fuerte contra quienes sostienen que Vallejo, en algún momento, alquiló su pluma o escribió movido por intereses subalternos, ajenos a los del intelectual honesto consigo mismo.

Ahora bien, siguiendo el testimonio de Georgette de Vallejo, ¿qué significó que la Editorial Cenit finalmente rechazara la publicación el cuento "Paco Yunque"? La respuesta es compleja y tiene que ver, desde luego, con las expectativas de la editorial, es decir, con la idea que entonces las editoriales (incluso las comunistas) tenían respecto de lo que debía ser un cuento para niños. En este sentido, el que la escritura del cuento esté, en sus inicios, ligada a la petición y luego al rechazo de una editorial de orientación comunista es un hecho que, desde nuestro punto de vista, es decisivo para entender lo que trató de hacer Vallejo al escribir "Paco Yunque" y lo que no comprendió la Editorial Cenit.

La necesidad de producir un arte proletario, hacia 1931, época de la redacción de "Paco Yunque", es para Vallejo importante. Prueba de ello es la defensa que hace de este tipo de textos en El arte y la revolución ${ }^{4}$. De modo que, si tenemos a un escritor convencido de la prédica marxista y de la necesidad de un arte de propaganda y agitación, resulta absolutamente lógico pensar que Vallejo se propusiera escribir un cuento para niños que cumpliera con responder a la ideología o a los supuestos del marxismo, y que, a la vez, desarrollara en la redacción del cuento las características del arte proletario. La negativa de la Editorial Cenit a publicar "Paco Yunque", bajo la excusa de ser un cuento triste, halla, de este modo, una primera explicación. Es posible postular razonablemente que para la editorial, la naturaleza de un cuento para niños, en tanto cuento proletario, no debía mostrar "las luces y las sombras de la conciencia clasista, los pasos y las caídas (...) las

\footnotetext{
${ }^{3}$ Para un mayor conocimiento del papel desempeñado por la Editorial Cenit revisar el artículo de Gonzalo Santonja (2002), incluido en la bibliografía.

${ }^{4}$ Ver en el libro citado el artículo "Ejecutoria del arte bolchevique" en que Vallejo explica el modo y los fines de este tipo de arte.
} 
lagunas, faltas, aciertos y vicios de las masas en sus luchas revolucionarias" como sostenía Vallejo (1973: 124), sino adscribirse a una perspectiva que privilegiara la representación de universos liberados de la angustia de vivir en un mundo injusto, sin tener, necesariamente, que idealizarlo.

Contra esta limitación o prejuicio que se sustenta en la idea del cuento para niños asociado a la fantasía y la irrealidad y la consiguiente normalización de una situación anómala o excepcional presentada en la historia, Vallejo realiza una segunda revolución: postula, a través de "Paco Yunque", un tipo de cuento realista alejado del estereotipo dominante que no evita la responsabilidad de confrontar al lector (en este caso un niño) con una realidad injusta con la que debe empezar a mantener una posición crítica.

\section{LA DIALÉCTICA VALLEJIANA}

Vallejo articula su pensamiento al materialismo filosófico y parte del principio de que lo que explica científicamente el lugar del hombre en el mundo es el conjunto de relaciones sociales, concreta e históricamente determinados, que lo rodea. Por ello funda su explicación de la realidad a partir de la praxis material dentro de la cual se halla inserto todo ser humano de forma inevitable. Vallejo concibe al mundo como un proceso, como una sustancia sujeta a una evolución histórica y al marxismo como una teoría en permanente proceso de corrección ${ }^{5}$.

La concepción artística de Vallejo es plenamente marxista a fines de los años veinte del siglo pasado y se funda en la dialéctica. Citémoslo: "Solo desde un punto de vista dialéctico es que puede denominarse y se denomina socialista al arte bolchevique. Dado que este interpreta y sirve a los intereses clasistas del proletariado, y este, a su vez, lucha por la instauración de la sociedad socialista universal, la idea del socialismo va implícita en la idea bolchevique" (1973: 25). De este modo, su adhesión, desde el clasismo proletario a la dialéctica materialista, le da potencia a su predicamento literario y lo persuade de la necesidad del cambio social. La dialéctica le permite acoger esta idea porque exalta en él el principio de que todo está sujeto a la ley de contradicción y, por lo tanto, a su transformación.

\footnotetext{
${ }^{5}$ Habría que anotar, en este sentido, que Vallejo era enemigo de los marxistas que llamaba "gramaticales", es decir, ese tipo de militantes que habían convertido a la doctrina de Marx en un "zapato de hierro". A estos "teóricos" los llamaba "doctores del marxismo" y les reprochaba la incapacidad de rectificación y corrección de las propuestas del marxismo. Ver en El arte y la revolución el apartado que titula, precisamente, "Los doctores del marxismo".
} 
La contradicción es esencial en Vallejo para acceder a cualquier clase de conocimiento y en ella funda su saber sobre el mundo y las relaciones sociales. Como para Marx, para Vallejo la dialéctica es la ciencia de las leyes generales del movimiento y en su narrativa lo que buscará es representar dialécticamente el conflicto de las diversas fuerzas que se contraponen en la sociedad. Por ello, en "Paco Yunque" serán visibles varios ejes de oposición básicos: explotador-explotado, riqueza-pobreza, injusticia-justicia, poderdebilidad, valentía-cobardía. Todo esto fortalece el profundo antagonismo en el que se funda la concepción del cuento y que apunta, sin duda, a las diversas formas de la lucha de contrarios. Vallejo es dialéctico, además, porque muestra, como postulaba el marxismo, la interdependencia y el vínculo inevitable de todos los aspectos que conforman la totalidad concreta.

El mundo para Vallejo no se compone de un conjunto de objetos terminados o de un proceso acabado, sino que está constituido por una dinámica de permanente contradicción sujeta por ello a continuo cambio. En su sistema de pensamiento nada permanece inmutable y por lo tanto nada hay que pueda ser considerado como absoluto ni mucho menos divino. De hecho, en su narrativa proletaria, la ausencia de referencias sagradas, inmutables o místicas ha desaparecido por completo para dar paso a la inevitable fuerza de la dinámica social. De otro lado, Vallejo implementa la perspectiva marxista para sostener que la solución de las contradicciones sociales es urgente y por ello impostergable. Como marxista, Vallejo aborda el estado de cosas y busca transformarlo a través de sentimientos como la indignación que busca fomentar en el lector a partir de la descripción de una situación de explotación y abuso. Su narrativa clasista, representada por El tungsteno y "Paco Yunque" niega un mundo, el de la injusticia social, y postula la extinción del Estado que sustenta esa iniquidad.

En una perspectiva materialista histórica, Vallejo explica la conciencia social del sujeto a partir de su ser social, es decir, a partir de las condiciones materiales en las que se desarrolla. Marx es claro en este aspecto central de su ideología en el prólogo a su Contribución a la crítica de la economía política: "En la producción social de su vida los hombres entran en determinadas relaciones necesarias e independientes de su voluntad, relaciones de producción que corresponden a una determinada etapa del desarrollo de las fuerzas productivas materiales" (citado por Lenin en su Carlos Marx y Federico Engels, 1977: 14).

Por ello, Vallejo describe en su narrativa clasista la estructura económica en la que se funda el intercambio social, a partir de la cual se establecen los patrones de juridicidad y por ende las relaciones de poder. No escapa a 
Vallejo la conciencia de que a partir de esta base real se construyen las formas de conciencia social que operan conflictivamente en un determinado momento histórico.

\section{3. "PACO YUNQUE", EL ARTE REVOLUCIONARIO Y EL CUENTO CLÁSICO INFANTIL}

Bastaría con decir que "Paco Yunque" es un cuento que pertenece a la tradición de la literatura realista de índole proletaria para alejarlo de los esquemas del cuento tradicional para niños, sin embargo presentaremos algunos argumentos para reforzar la idea de que estamos frente a un cuento infantil cuyo motivo y estrategias de representación se vinculan con la ideología marxista.

Con respecto a los postulados de la narrativa infantil, vigente en los tiempos de Vallejo, un cuento para niños debía responder a ciertas características que lo vinculaban con la explotación de la fantasía (con la clásica animización de animales y plantas), cierta economía narrativa y un final edificante a partir del cual el joven lector podía y debía ganar cierta confianza en sus iniciales y conflictivas relaciones con el mundo. Nos referimos a cuentos que presentaban un conflicto, no muy complejo por cierto, pero

que siempre se resolvía de manera positiva y que servía para educar al niño sobre ciertos valores como la honradez, la honestidad y hasta la pulcritud.

A diferencia de los cuentos infantiles tradicionales (que construían un espacio problemático que se contraponía a otro de protección o de seguridad para el niño frente a la inclemencia de un mundo hostil) "Paco Yunque" nos instala, precisamente, en medio de un mundo regido por leyes impuestas por un orden injusto cuya mayor característica es la inestabilidad y la angustia. En el cuento no se procura la evasión del niño hacia universos alternos en los que reine otra lógica u otro orden y mucho menos se representa una situación problemática que se normaliza después de enfrentada la situación conflictiva, sino todo lo contrario. En la historia queda legitimado, por el reconocimiento de los demás, el portador de la injusticia.

El mundo de Paco Yunque es opaco, es decir, contradictorio, ofensivo a la moral del justo e indignante. En él no se realiza ningún desplazamiento a un mundo fantástico luego del cual se produzca una traducción del propio mundo con nuevos elementos que faciliten su interpretación. En "Paco Yunque" la situación descrita es tan brutal que al joven lector solo le queda procesar la información con las herramientas de una incipiente ética que se 
ve presionada por las demandas de una situación de injusticia que hay que comprender de un modo solidario.

En "Paco Yunque" asistimos a una representación asaz realista en la que la fuerte presencia del horizonte económico y de la estructura de organización social cumplen con el propósito de construir un fuerte verosímil en el que espacios, acciones y personajes pueden ser reconocidos por el lector. No hay pues un intento de evadir al niño de su realidad. Es más, es un cuento que busca hacer patente la injusticia y el abuso en un universo pueblerino articulado a un capitalismo incipiente. Su interés, como es evidente, aparte del propiamente vinculado con la vida de un niño proletario, se centra en la exploración del horizonte económico en medio de las necesidades de una madre alienada por la necesidad de sobrevivir.

Vallejo sostenía que el arte revolucionario debía ser directo, simple y lo más descarnado posible (1973: 123). Confiado en que la elaboración artística de este tipo de literatura debía ser mínima y que la emoción debía lograrse por el camino más corto y a quemarropa, Vallejo emplea en "Paco Yunque" ciertas estrategias de representación en las que la claridad expositiva y la eliminación de la ambigüedad se convierten en los recursos de un arte cuya crudeza se convierte en el instrumento de la denuncia.

Un elemento importante de la poética que vincula a "Paco Yunque" con el arte revolucionario tiene que ver con que a Vallejo le interesaba formular interpretaciones siempre ajustadas al marxismo a través de la representación de lo que para el realismo proletario de entonces era fundamental: el tipo. Construir situaciones a partir del tipo que permitan precisamente visibilizar de manera clara las contradicciones sociales. Por eso la tipicidad y la simplicidad que se observa en el relato son bastante gráficas lo cual, por deliberado, demandaría de la crítica una reflexión más detenida con respecto a la función y objetivos de este tipo de literatura antes que su condena.

Tenemos por un lado a Humberto Grieve que es el hijo de un inglés gerente de una empresa de ferrocarriles y alcalde del pueblo, y por el otro tenemos a los desposeídos, a la familia Yunque que son los sirvientes de los Grieve. Humberto Grieve, en el cuento, es un niño que ostenta mucho poder económico, que sabe humillar, que reproduce los modos clasistas familiares y que maltrata a sus semejantes trasladando la dinámica de dominación familiar al colegio. Así como la madre y el padre de Paco Yunque son los sirvientes de los padres de Humberto Grieve, así, desde la perspectiva de Humberto Grieve, Paco Yunque es su sirviente,

$\mathrm{Al}$ resolver deliberadamente el cuento de forma negativa, es decir, de forma nada edificante, Vallejo se opone abiertamente a todas las morale- 
jas y moralinas de la literatura narrativa infantil. Resulta inédito para una tradición en la que el bien siempre termina triunfando sobre el mal, que Vallejo optase por la salida contraria. Vallejo nos muestra una situación final de indignidad padecida por Paco Yunque y al optar por un final en el que el personaje termina llorando desconsoladamente sin poder cambiar su situación, nos traslada la indignación producida por la derrota sufrida por niño protagonista. De este modo, la historia de Paco Yunque generará en el lector una disposición a la acción transformadora. Pareciéramos escuchar a Vallejo decir que hay que cambiar esa situación o demandarnos la realización de un acto de justicia a partir de este cuento, acto ya no textual, sino efectivo.

$\mathrm{Al}$ apostar por la ausencia de la moraleja positiva, Vallejo respeta escrupulosamente la lógica interna del relato. En realidad no es posible esperar un desenlace diferente. Como personaje, Paco Yunque no puede transformarse en un niño valiente después de sufrir la sistemática humillación de Humberto Grieve e incluso la humillación de su propia madre. Como se puede apreciar, la dimensión temporal del cuento, que sólo dura una hora, no lo permite. El hecho de que este niño termine llorando es completamente lógico después de analizar la trayectoria psicológica del infante. La derrota de Yunque es la derrota de su clase social, lo cual no implica que el cuento sea una loa a la derrota, pero sí un advertencia a la clase de la que proviene; una llamada de atención con respecto a la clase de retoños desclasados o carentes de una conciencia de su propia condición, condición que se extiende a todo el sector obrero que Paco Yunque representa.

Será, quizá, por eso que la Editorial Cenit rechazó el cuento. Es decir, por desarrollar una historia triste, en la que, como es visible, la injusticia realiza plenamente sus objetivos sin que al final pueda avizorarse alguna esperanza, un final diferente en el que la rectificación de la situación de injusticia hubiese creado las condiciones para el desarrollo de la confianza en el niño lector. El hecho de que la bondad sea ofendida, que la buena voluntad sea despreciada, que se premie al deshonesto, debe haber producido en los editores de Cenit una aprensión similar a la que puede producir el desprecio por valores como la verdad y el respeto solidario por el otro que en el cuento quedan mancillados.

A un niño desprevenido y sin la guía adecuada, la lectura de este cuento podría desmoralizarlo o confundirlo. Al no castigarse el abuso, ni la prepotencia, al niño lector de "Paco Yunque" podría quedarle el campo libre para ser implacable con sus débiles compañeros. ¿No es verdad acaso que los niños a esa edad viven una etapa difícil y que hay que orientarlos con sumo cuidado porque pueden volverse injustos y abusivos? 
Y bien, ¿porque Vallejo presenta de modo tan poco edificante esta historia? Vallejo les dice a los jóvenes lectores que esto pasa en la realidad. Vallejo está proponiendo la posibilidad de leer un tipo de literatura orientada a un universo infantil fomentado en los jóvenes lectores una conciencia clara de lo que es la injusticia. Vallejo apuesta por una narrativa para niños que los confronte con una realidad atroz. Vallejo no ve al niño como un ser humano de segunda categoría al que hay que embrujarlo o hechizarlo con historias ajenas a este mundo. Él observa al niño como alguien con una gran capacidad de discernimiento en aras de construir a un lector sensible al dolor, un lector atento a las inconsistencias de este mundo.

\section{4. "PACO YUNQUE” Y LA LITERATURA PROLETARIA MARXISTA- LENINISTA}

"Paco Yunque" cumple con un requisito esencial para ser considerado un cuento proletario: nos muestra un momento de nuestra historia contemporánea en el que una familia campesina se integra, a partir de una relación de servidumbre, a la dinámica de explotación del capitalismo transnacional representada por una empresa de ferrocarriles, la Peruvien Corporation dirigida por Dorian Grieve, un inglés que concentra además de poder económico, el poder político al ser el alcalde del pueblo. "Paco Yunque" nos muestra los modos de inserción de la familia burguesa de los Grieve y lo que su presencia genera en el pueblo constituido por campesinos provenientes del campo. Asistimos, de este modo, a la obscena mostración de una dinámica de explotación e insolidaridad humanas de la que los hijos de ambas familias serán conflictivos protagonistas. A eso se refiere Antonio Cornejo Polar cuando sostiene que, hacia 1931, Vallejo busca, después de la experiencia de la escritura de El tungsteno, "reseñar un estado de cosas e interpretarlo a la luz del marxismo, construyendo para ello una argumentación ejemplar; esto es, un suceso, un ambiente, unos personajes que permitieran la inmediata captación de la realidad y, que, luego permitieran la interpretación correcta del sentido social, económico, político de esa misma realidad" (1969: 322). Está, creemos, en 1931 la naturaleza de su poética, fundada, ciertamente, en una enfática conversión al marxismo.

Esta orientación en la forma de representación de la realidad configura varios planos de significación que nos permite entender, con claridad, la dinámica de explotación en todos los niveles que comporta la experiencia 
de la dominante familia Grieve y la sumisa familia Yunque. Desde aquel que supone la implantación capitalista en un país de rasgos aún feudales como el Perú de los años veinte, hasta las relaciones de corte esclavista entre los jóvenes protagonistas, Humberto y Paco.

"Paco Yunque" es un cuento proletario porque hunde sus raíces en una coyuntura social y política concreta y la observa desde el mirador del clasismo, a diferencia de la literatura socialista que no está anclada al carácter contingente de la lucha de clases. En este sentido el cuento de Vallejo explota la coyuntura de la penetración capitalista a comienzos de los años veinte en el Perú, esto es, el momento en que se produce la violenta intervención del capital foráneo en la economía nacional. El objetivo de Vallejo es operar sobre ese hecho y estudiar sus consecuencias, a nivel familiar pero también individual, en la figura más frágil de esa familia: un niño campesino trasplantado a un pueblo que el cuento permite imaginar como una pequeña ciudad de provincia. A partir de esta línea argumental, a la que se suma la inmigración europea de índole económica, podemos sostener que el cuento de Vallejo se instala en la tradición temática de la narrativa naturalista hispanoamericana.

En este sentido el cuento "Paco Yunque" es un texto que interpreta y sirve a los intereses clasistas de un proletariado que Vallejo avizoraba como un cuerpo organizado y fuerte, pero aún inexistente, por lo menos en ámbitos pueblerinos como el representado en el cuento. Por ello, en principio, es un texto que busca identificar las bases de un proletariado en formación, pues en esencia no están representados personajes plenamente proletarios ${ }^{6}$ y mucho menos con una desarrollada conciencia de clase. Y sin embargo "Paco Yunque" no deja de ser un cuento proletario, porque cumple con el requisito de ser un cuento de propaganda y agitación revolucionaria. Es posible que Vallejo concibiera la idea de "Paco Yunque" tratando de llevar a la práctica la escritura de un cuento marxista para niños, cuento que, desde luego, apenas podía concebirse en la época, si nos atenemos a los modelos de cuentos para niños que se escribían entonces.

De otro lado, "Paco Yunque" se corresponde con el cuento proletario porque se articula a la reivindicación de la lucha de clases como eje a partir del cual solo es posible entender el curso de la historia y su proyección de

\footnotetext{
${ }^{6}$ Siguiendo la lógica marxista, la familia de Paco Yunque solo es proletaria en esencia (no son obreros, por ejemplo). Al no poseer medios de producción, sólo tiene para subsistir su propia fuerza de trabajo. Eso los convierte en proletarios al margen de si su trabajo se realiza en una fábrica de producción masiva, como lo hacen propiamente los obreros.
} 
cara al futuro. Es proletario, además, porque configura en su seno la indignación necesaria sin la cual, según la literatura de este tipo, no se puede producir el cambio. Por ello es, a la vez, didáctico, simple, pedagógico, en la medida en que busca enseñar, concientizar, educar, tomando como motivo central al propio horizonte educativo en el que debieran resolverse los conflictos de una conciencia en formación como la de "Paco Yunque". ¿Estos elementos hacen del cuento una pieza menor?

Contra quienes sostienen que la literatura proletaria es siempre edificante o constructiva o que proyecta imágenes triunfalistas, ideales o definitivas, Vallejo defiende la idea de que este tipo de literatura es absolutamente coyuntural y cíclica, pero que debe cumplir con la función de "atizar y adoctrinar la rebelión y la organización de las masas para la protesta, para las reivindicaciones y para la lucha de clases (...) es un arte de proclamas, de mensajes, de arengas, de quejas, cóleras y admoniciones" (1973: 26). Esta cita nos permite entender el sentido de un cuento como "Paco Yunque" en el que queda plasmada, según Vallejo, esa "elocuencia agresiva contra el régimen social imperante" (1973: 26). Por ello, explícitamente, el cuento lanza una acusación contra un orden social injusto desde un punto de vista clasista, punto de vista que se construye desde la conciencia de un narrador plena y solidariamente identificado con los intereses de ese proletariado sin conciencia de clase.

A diferencia del arte socialista que responde a los intereses comunes de todos los hombres y que reivindica la obra de artistas cuya contribución se proyecta por encima de las clases sociales, el arte proletario fomenta una posición crítica contra una clase social específica, la burguesía, y contra el sistema que la sostiene, el capitalismo. "Paco Yunque" en este sentido es un cuento proletario en la medida en que se constituye en una literatura de clase orientada a defender los intereses de ese proletariado en formación y a fomentar el desprecio por el modo de vida burgués. Como lo sostuvo Lenin, la literatura proletaria lo es porque es una literatura de clase y porque se encuentra solventada por los principios dictados por el Partido Comunista, principios que aunque puedan sorprender, Vallejo llegó a respetar: "La literatura proletaria debe servir a los intereses de clase del proletariado $y$, específicamente, debe enmarcarse dentro de las directivas y consignas prácticas del Partido Comunista, vanguardia de las masas trabajadoras" (1973: 61).

En "Paco Yunque" es visible ese "odio ardiente a la sociedad capitalista" y ese afán por destruir sus fundamentos injustos, como decía el propio Vallejo (1973: 61). De este modo, y a través del narrador, es patente la gran 
simpatía y solidaridad frente al segmento social al que pertenecen los Yunque, en este caso un segmento alienado, y por lo tanto indefenso, ante la ciega inclemencia del sistema.

En el plano simbólico, no menos importante en el cuento 7 , Vallejo trabaja con dos símbolos bastante conocidos, propios del obrerismo revolucionario leninista: la hoz y el martillo. Estos elementos se encuentran en la base ideológica del texto y cumplen un papel relevante en el plano de la construcción de los personajes, sus relaciones y los motivos que los impulsan a la acción. En el cuento, Paco Fariña y Paco Yunque son o terminan siendo amigos a partir de una solidaria relación que, a pesar de la desconfianza, los hermana de algún modo. El hecho de compartir el mismo hipocorístico, Paco, fortalece la alianza entre los dos. En ese sentido, si uno observa bien, el apellido "Fariña", traducido al español, significa harina, un elemento que nos vincula con el universo agrícola, campesino, es decir con la hoz. Yunque, por su lado, refiere al metal, al soporte de hierro que sirve para martillar el metal con el fin de darle forma y, por ende, al universo obrero.

\section{LA CONCEPCIÓN MATERIALISTA DE LA HISTORIA Y LA “LUCHA DE CLASES” EN “PACO YUNQUE"}

En "Paco Yunque", Vallejo explica, gracias a su formación marxista, la conciencia social de los personajes a partir de las condiciones que articulan su existencia material o a partir de lo que los marxistas llaman ser social. Vallejo en el cuento cumple con describir marxistamente "las relaciones de producción que corresponde a una determinada etapa del desarrollo de las fuerzas productivas materiales" (Lenin citando a Marx, 1977: 14).

El horizonte económico del cuento nos muestra, en esta dirección, un estadio de desarrollo incipiente, pero marcadamente capitalista, en el que las relaciones de patronazgo y servidumbre establecen una dinámica coercitiva, injusta y alienante caracterizada por una cadena de explotación de una clase a otra y de un individuo a otro, que se ceba en el más débil. Es evidente que, en términos de clase, el núcleo social al que pertenece Paco Yunque es incapaz de advertir críticamente las condiciones de dominación

\footnotetext{
${ }^{7}$ Este aspecto ha sido sumamente trabajado por críticos como Ricardo González Vigil y Roland Forgues, cuyas aproximaciones han privilegiado la dimensión marxista del cuento "Paco Yunque”.
} 
económica que padece y por lo tanto incapaz de observarse a sí misma como una organización política y mucho menos ser consciente de la función histórica que le corresponde asumir dentro de la lógica del desarrollo social marxista. Por lo tanto, la posibilidad de la formación de una clase consciente de sus propios intereses, en "Paco Yunque", es inexistente.

Por ejemplo, el comportamiento de la madre, con respecto al propio Paco, nos demuestra la carencia de una conciencia respecto de su situación de clase y, más bien, refleja las alienantes condiciones de vida en la que los seres humanos son incapaces de establecer relaciones entre su modo de vida, marcado por relaciones económicas, y el mundo de las relaciones en el que se maneja la política, mundo que, finalmente, decide su lugar en la sociedad. Es evidente que la madre de Paco se siente agradecida por ser la sirvienta de los patrones Grieve y que la inmediata satisfacción de sus necesidades ha pasado a constituir el mayor impedimento para el desarrollo de una conciencia de clase. No existe, pues, un proyecto político en el que el núcleo social de Paco Yunque pueda reconocerse.

De este modo, en el horizonte social que construye el cuento se hace patente, como quiere el marxismo, el modo de producción de la vida material y la forma en que este modo condiciona el proceso de la vida social, política y espiritual. Vallejo se ocupa de hacer visible la base económica en la que se funda la vida, base que por cierto queda intacta en el cuento, pero que se asegura de mostrar en toda su injusticia. Y si bien en "Paco Yunque" el conflicto se da en un ámbito escolar, queda clara la importancia que tiene la injusta dinámica de las fuerzas productivas y la base material que organiza ese mundo en ese conflicto, dinámica que se reproduce en la conducta prepotente y absurda de Humberto Grieve.

En relación al modo en que el cuento representa la lucha de clases, habría que anotar que nos muestra aquello que Vallejo denominaba "las luces y las sombras de la conciencia clasista" (1973: 124) y que en el caso de "Paco Yunque" se deja traslucir por esa ausencia de conciencia de clase que la servidumbre y la opresión han terminado por destruir en la madre y en el niño.

Aunque queda claro que el protagonista Paco Yunque no desarrolla ninguna estrategia relacionada con su propia emancipación respecto del dominio que Humberto Grieve ejerce sobre él, el cuento sí evidencia en Paco Fariña una conducta insumisa e independiente que le sirve a Yunque como un ejemplo del camino que debe seguir en la escuela. Paco Fariña es plenamente consciente de las determinaciones de clase y de las motivaciones que se encuentran detrás de la conducta de Humberto Grieve. Este último, por 
lo demás, y a lo largo del cuento, no hace más que afirmar la posición social que le ha tocado vivir como hijo de un burgués y en las condiciones de vida que lo rodean y que marcan una diferencia entre él y sus compañeros de aula. Por ello es evidente que en el cuento se perciba un antagonismo de clase sin el cual, por cierto, la literatura proletaria dejaría de serlo. En ese sentido, el cuento incide en la relación absolutamente asimétrica entre las clases sociales y representa las inequitativas cuotas de poder que a cada una de ellas le corresponde.

Por ello, en "Paco Yunque" está planteada, implícitamente, la desaparición de la clase burguesa que representan los Grieve. Para los marxistas como Vallejo, esa desaparición se avizora como inevitable dada la gran iniquidad que sostiene al sistema capitalista en el que los proletarios como los Yunque solo tienen, como medio de sobrevivencia, su fuerza de trabajo, de la que provienen los beneficios de los dueños de los medios de producción. Dorian Grieve, al ser presentado como el patrón de los Yunque y como gerente de la empresa de Ferrocarriles Peruvien Corporation se convierte en el eje de ese sistema, en el dueño del valor que produce la fuerza de trabajo de los Yunque. En otra dimensión, eso es lo que sucede cuando Humberto Grieve se apropia de la tarea realizada por Paco Yunque y la presenta como propia al profesor. A su manera, violenta también, Humberto Grieve reproduce el despojo capitalista de la fuerza de trabajo, en este caso intelectual, ofrecida por Paco cuando éste convierte la tarea no en una mercancía pero sí en capital simbólico, capital que, desgraciadamente, le servirá a Humberto para ser reconocido y admirado por sus compañeros de aula.

\section{CONCLUSIONES}

A través de "Paco Yunque", Vallejo dota a la narración de una orientación abiertamente marxista a partir de la aceptación del materialismo dialéctico como instrumento ideológico adecuado a la interpretación de los hechos de la realidad capaces de ser integrados en una totalidad concreta.

"Paco Yunque" se corresponde con la llamada literatura proletaria cuya función coyuntural es la de fomentar la liquidación de la clase burguesa y alentar la organización del proletariado en torno a los intereses del Partido Comunista Internacional. En ese sentido el texto no se corresponde con la literatura socialista que obvia la confrontación y se presenta como un espacio para la conciliación de las clases sociales ya democratizadas. De hecho el cuento "Paco Yunque" está en contra de la conciliación de clases y busca el fortalecimiento de la conciencia clasista del proletariado. 
Frente a los modos del cuento para niños tradicional, "Paco Yunque" niega sistemáticamente la evasión del niño por la fantasía y lo confronta con un mundo asaz realista y violento.

El cuento no configura plenamente la conciencia clasista de la familia Yunque ni mucho menos la conciencia de un niño proletario como Paco, hecho que sucederá, luego, con algunos personajes de la narrativa obrera peruana de los cincuenta. El cuento, más bien, disecciona la naturaleza de la conciencia desgarrada de un niño proletario que sufre los avatares del abuso en un contexto escolar y que no obstante trata de comprender dramáticamente su lugar en el mundo.

\section{REFERENCIAS}

Cornejo Polar, A. (1969). "Sobre 'Paco Yunque'. En: Delgado, Washington y Milla Batres, Carlos (eds.). Homenaje Internacional a César Vallejo (pp. 322324). Lima: Visión del Perú.

Monguió, L. (1960). César Vallejo. Vida y obra. Lima: Perú Nuevo.

Lenin, V. I. (1977). Carlos Marx y Federico Engels. Pekín: Ediciones en Lenguas Extranjeras.

Santonja, G. (2002). "Breve perfil de la Editorial Cenit (Madrid, 1928-1936)". Recuperado de www.dialnet.uniriosa.es/servlet/articulo? codigo $=237414$

Vallejo, C. (1951). "Paco Yunque". Apuntes del Hombre, año I, No 1, julio.

Vallejo, C. (1973). El arte y la revolución. Lima: Mosca Azul.

Vallejo, G. de (1959). “Apuntes biográficos de César Vallejo". En Vallejo, C., Los heraldos negros. Lima: Perú Nuevo. 